\title{
Agaphylax, a new limnephilid genus (Trichoptera) from the Balkan: Lineage ranking by adaptive paramere
}

\author{
J. OLÁH ${ }^{1}$, T. KOVÁCS ${ }^{2} \&$ H. IBRAHIMI ${ }^{3}$ \\ ${ }^{I}$ János Oláh, Residence postal address: Tarján u. 28, H-4032 Debrecen, Hungary. \\ E-mail:profolah@gmail.com \\ ${ }^{2}$ Tibor Kovács, Mátra Museum of the Hungarian Natural History Museum, Kossuth L. str. 40. H-3200 Gyöngyös, \\ Hungary.E-mail: koati@,t-online.hu \\ ${ }^{3}$ Halil Ibrahimi, University of Prishtina, Faculty of Mathematics and Natural Sciences, Department of Biology, \\ Mother Teresa p.n., 10000 Prishtina, Kosovo.E-mail: halilibrahimi@yahoo.com
}

\begin{abstract}
A new genus, Agaphylax gen. nov. is erected for a new species, Agaphylax balcanicus collected in the Balkan Peninsula (Macedonia). The new genus is established primarily on the uniquely organised paramere with character combinations of the cerci and paraproct complex. This unique taxon confirms recent findings in Dicosmoecinae and Drusinae subfamilies and Hesperophylacini tribe suggesting that parameres may have high ranking value and real capacity to detect ancestral and contemporary lineage divergences in the Limnephilinae subfamily. Theoretical aspects of taxonomical ranking are discussed briefly in order to understand the biological ranking value of the paramere traits: semiotic/semiologic/semantic/hermeneutic epistemology; specific/generic, ancestral/derived, complex/simple, adaptive/neutral characters; speciation super traits/limits of single traits; unweighted/weighted characters. Ancestral paramere structures, the basic plesiomorphic paramere patterns are presented along transformation series of simplification in the five tribes of Limnephilinae subfamily, as a working hypothesis for a future comprehensive paramere revision.
\end{abstract}

Keywords. New limnephilid genus, taxonomic ranking, speciation, super trait, paramere organisation.

\section{INTRODUCTION}

$\mathbf{I}_{\mathrm{d}}^{\mathrm{n}}$ the course of the Hungarian Trichoptera studies on the Balkan Peninsula we have collected an unknown limnephiline species with strikingly unique paramere structure. The broad wing shape, the anastomosal pattern on forewing, the not particularly massive genital structure of the new species resembles the adults in the Stenophylacini tribe of the Limnephilinae subfamily, but not fit well with any of its known genera. Moreover, the right angled and ramose seta-less apical region of the vertically flattened paramere does not fit well either with the basic paramere pattern of any of the known tribes. Based on this unusual paramere with apical upright branching here we describe the new genus Agaphylax and the new species Agaphylax balcanicus with the possibility of future tribe ranking. The ramose apical region of the adaptive trait of the parameres signifies the tribe ranking capacity within the subfamily. However, to understand its real ranking value systematic comparative studies are required on the paramere as well as on the related genitalic characters in the entire Limnephilinae subfamily. In this paper we describe the new genus and species with a brief survey on ranking theory and with an outline of the possible paramere organisation strategies in the tribes of the subfamily.

It is not easy to determine the taxonomic rank of our newly discovered taxon. Phenomics, devoid of human and financial resources, is badly suppressed, particularly the character ranking with morphological characters. Phenomic criteria of biological ranking are not well grounded. The empirical reality is replaced by virtual surrogacy of molecular clades. Taxonomic impediments produced other funny surrogacies as well in the declining taxonomy that are the replacement of 
species by morphospecies in biodiversity assessment (Oliver \& Beattie 1996) or by higher ranked taxa like genera or families (Bertrand et al. 2006) in assessing community responses to environmental drivers (Bevilacqua et al. 2012). In our time these taxonomical surrogacies are the striking signs and the painful anti-science consequences of the staggering taxonomy. These wasteful trials give no any semiotic, semiologic, semantic or hermeneutic background to taxonomic ranking practices.

Evolutionary clades of generic rank of natural kinds are inherently variable in different groups of organisms. Additionally, genus ranking as nominal kind is semi-subjective and has its own tradition in every group of organisms. Phenomic and genomic construals in genus designation are not standardized and involve highly varying groupdependent phenomics and divergence histories. Organisational closure of constraints in bacterial autonomy against divergences is significantly modified at higher organisation levels which have much more emergent components. Additionally, rank allocations in current taxonomic practices are limited by heterogeneous mixture of various historical and contemporary views dominated by genomics over phenomics. Ranking in phylogenetic trees is ruled by molecular clades and resulted in empirically non-nested taxa. The virtual molecular clades of taxonomic surrogacy lack justification (Bertland et al. 2006). Vainly beating the air with this molecular trials, the rate at which new taxa are described has "barely changed" in the last 100 years. Taxonomy is almost the same as it was 100 years ago (Baum 2009). Not surprising that we face difficulties to cope with the phenomic ranking of our unique taxon collected in Macedonia.

There are only uncertain biological ranking ideas for limnephilid genera and tribes created more than half century ago (Schmid 1955). Later, the unreliability of tribe definitions in separating Limnephilini and Stenophylacini tribes was reminded (Schmid 1998) and re-examined (Malicky 2001). Due to the lack of sound genus and tribe ranking criteria in Limnephilinae subfamily se- veral taxonomical questions remained unsettled (Grigorenko 2002). There was a significant trial to corroborate phylogenetically informative character phenomics in order to polarize characters and to reveal transformation series in searching for synapomorphies (Vshivkova 2006, Vshivkova et al. 2007). Binary character coding, polarized transformation series were established and analysed in a huge number of morphological characters. However, without real biological character weighting the final result of various lineages with various bootstrap values has no real basis for the hermeneutics of the subfamily. Increasing the number of unweighted morphological or molecular characters doesn't help us much to find the speciation or diverging traits, either phenomic or genomic. Only phenetic species concept in taxonomy and phenetic clade construction in systematics believes that a system can be reduced to the sum of its part. Nevertheless both pheneticists and cladists prefer to apply large set of evidence be considered. Quantification alone doesn't create biological interpretation. This quantitative masking procedure of applying as much number of trait evidence as possible does not give adequate importance to apomorphic characters of "evolutionary novelties" which are inherently more informative as well as has higher weight and ranking value in phylogenetic relations. Finding speciation traits or genes responsible for reproductive isolation alone can delineate taxa. We cannot avoid a value judgement stating that one character is a better indicator of phylogeny than another.

\section{THEORY OF RANKING}

In taxonomy we face every day the questions which characters or character combinations indicate species or genus level ranking along the taxonomic hierarchies? Which level of phenomic or genomic divergences denotes species or genus level differences? We establish species and genera and other higher hierarchies of nominal kinds by characters and character combinations of natural kinds. During this taxonomic practice we apply unconsciously the procedures and theories of various sciences: (1) semiotics (general science of 
sign), the triadic view of the world (sign, object, mind) as an act of representation; (2) semiology (applied science of signs) as an act of articulation based on Kantian dichotomy of phenomenal (mental: subjective) and noumenal (material: objective) worlds; (3) semantics (science of meaning), the relation between sign or set of signs and what they denote, their semantic content; (4) hermeneutics (science of interpretation): Heidegger's epistemological hermeneutics: idealism that our understanding determines entities or realism that nature exists and science explains how it is structured. Regardless of our scientific trials intrinsically linked, unavoidable mistakes obscure our practice in character ranking and compromise its epistemic utility in pessimistic meta-induction. There are a few pertinent questions worth to review briefly. They may help us to answer the question; how to distinguish character combinations in order to delineate taxa and to establish taxonomical hierarchies. Which character is specific or generic? Which character state is ancestral or derived? Which character has higher ranking value? Does complete/complex or simple trait represent higher ranking value? Does adaptive or neutral trait offer higher ranking value? Why single character is inadequate? Why unweighted character is inaccurate? Why and how adaptive traits compensate for ranking with single and unweighted characters?

\section{Generic ranking by phenomics}

Does this unique ramose paramere apex fulfil or satisfy alone the ranking criteria of genus or tribe in Limnephilinae subfamily? To identify any particular organism it is essential to specify at least the rank of the species and the rank of the genus. Taxonomic ranks are objective natural kinds; they are clade particulars (set of individuals) in the phylogeny; but they denote subjectively defined constructs of nominal kinds; rank designations are based on dissimilarities between individuals or groups of organisms. In the everyday discourse and even in rigorous scientific communication there are still imprecision over the meaning of the genus: genera are (1) objects of natural kinds; (2) evolutionary units; (3) lineage clusters; (4) cluster of populations; (5) ecological entities; (6) morphologically distinct entities; (7) formal names of nominal kind.

Specific and generic characters. Trait is the phenotypic variation of a character. For instance in the limnephiline subfamily the pattern of paramere head is a character, the bilobed head shape pattern is a trait. Character is to be understood in the sense of quality. Such qualities can either be inherited or acquired over a period of time, with interaction between intrinsic and extrinsic environment. A phenotypic trait, or simply trait, is a distinct variant of a phenotypic characteristic of an organism; it may be either inherited or determined environmentally, but typically occurs as a combination of the two. A trait is a characteristic or a feature of a species that is inherited normally genealogically.

All the species of a genus resemble each other, and in which they differ from allied genera, are called generic characters. Traits in which species differ from other species of the same genus are called specific characters. Specific characters are more variable than generic. Parts which have recently and largely varied, being more likely still to go on varying than parts which have long been inherited and have not varied. Secondary sexual characters are highly variable. It will also be admitted that species of the same group differ from each other more widely in their secondary sexual characters, than in other parts of their organisation.

Species are nested within genera, genera within families, family within orders, and order within classes. The same Linnean system of ranking has survived the elucidation of evolution, its driving force, genetics, population genetics, and the revised concept of monophyly as well as the revolution of molecular phylogenetics. In recent years criticisms focused on instabilities of taxon names produced by shifts in ranking practice based on shared traits rather than shared ancestry and on inconsistency, the lack of standardization of taxonomic ranks across different kinds of organisms. The trial to standardize taxonomic 
ranks by the absolute time of evolutionary origin measured by simple, relaxed or calibrated molecular clock, the temporal banding approach proved that taxa in Linnean ranking are highly nonstandardized, temporary. Various clades in different groups of living creatures of the same taxonomic rank can be associated with very wide range of evolutionary ages (Avise \& Liu 2011). Similarly to the molecular clock procedure, the temporal banding was again a primitive wishful trial, a simplistic, virtual mathematical abstraction of reality: how can anyone compare primates, caddisflies, fungi, plants and bacteria genera and suppose they have similar absolute evolutionary time of origin?

Ancestral or derived? To distinguish between present-day descendant and long-dead ancestors remained a permanent unresolved reverent task of taxonomy. What were the characteristics of extinct ancestor? Which characters are more ancestral (earlier organised) or more derived (recently organised)? How to establish reliable character ranking? To establish which traits or character states are adaptive versus neutral or plesiomorphic versus apomorphic we rely upon evidences of sexual integration as well as considering the universal principles of commonality, diversity, generality, hierarchy, locality, and parsimony (Winther 2009, Schmitt 2016, Oláh et al. 2017). We use an empirical synthetic method for character definition by combining observed conditions along examined entities gained with analysing character by character or taxa by taxa based on observed ranges of variations. This adaptive-neutral distinction has remarkable potential in coalescent theory that is in this retrospective stochastic procedure to follow genetic drift backward along genealogy of antecedents to the most recent common ancestor, the co-ancestor of coalescent. We apply both gross and fine phenomics to evaluate character polarity (plesiomorphic or apomorphic) or character ranking (genus or species) with empirical evidences, not with mainstream genomics of virtual DNA sequences having only very limited or almost zero knowledge on relevant functional or morphological realities of biological organisation.
Complex or simple? In caddisfly phylogeny Ross (1956) preferred the simple, Schmid (1958) argued for the complete structure. According to the Williston's law the structures tend toward reduction: structural parts are reduced by loss and fusion (Williston 1914). A general evolution pattern of reduction in structural parts was demonstrated by Gregory (1935). An ancestor must be constituted by the integration of the largest possible number of characters (Schmid 1979). Based upon these considerations we have selected the structurally most complex parameres for the ancestral plesiomorphic state both in the Potamophylax nigricornis species group (Oláh et al. 2013) and in the Allogamus genus (Oláh et al. 2014). Our decision is confirmed by the simple fact that the ancestral species with the most complex paramere has the largest distributional area, compared to large series of diverged peripatric sibling species with reduced complexity of parameres and with small distributional area. Nevertheless we have considered that the terms simple, complex, primitive, generalized, specialized, are all strictly comparative (Ross 1956, Schmid 1958).

Complexity could arise, not by incremental addition but by incremental subtraction (Oláh et al. 2014). The reduction in the number of structural parts could be associated with increasing complexity (Esteve-Altava et al. 2013). Complexity may increase with complementary qualities associated to the decrease of structural units. Reduction of elements is compensated (1) by anisomerism, that is by specialization of the structures (measured by dissimilarity of connectivity and heterogeneity); (2) by the number of unpaired structures as a side-measure of anisomerism (fusion of two or more pre-existing structures, representing the most modified, specialized ones); (3) by density of connections (more connected is more complex); (4) by characteristic path length (speed of information flow), (5) by cluster development (loops of connections, integration, modularity). Specialization by simplification could be an inherent complexity increase. Parts tend toward reduction in number, with the fewer parts greatly specialized in function. Early excessive 
complexity followed by adaptive reduction is a possible route to adaptation. More advanced structures can have fewer parts.

Adaptive or neutral? To establish which traits or character states are adaptive versus neutral we rely upon evidences of sexual integration at least in our studies on speciation traits of parameres. Genome complexity is correlated with morphological complexity and driven primarily by nonadaptive stochastic mechanisms, rather than by adaptive evolution (Lynch 2006, Yi 2006). These questions emerged important for paraproct and paramere structures, especially, when their nonneutral, adaptive sexual selection driven evolution become more documented (Oláh et al. 2012, Oláh \& Ito 2013, Oláh et al. 2013, Oláh et al. 2014). Speciation traits of the phallic organ with titillating or harming functions directly involved in sexual selection processes diverge into variously complex structural patterns fitting to perform their multiple and complex functions in the initial stage of divergence (Oláh et al. 2013). Nevertheless, species delimitation and character ranking in tree inferences are especially difficult in recent contemporary divergences when different loci/structures have different histories in gene clouds along the gene and species tree discrepancies or reticulations (Meara 2010).

Why single character is inadequate? Each taxon has infinitely large number of phenomic and genomic characters that can be used as identifiers. Any taxa differ in indefinitely large number of phenomic and genomic characters that can be described in infinite number of ways. Moreover described taxa are inherently transient. Difficulties arise because all extant species are a mix of ancestral and derived characteristics and not the extant organism itself that is ancestral/"primitive"/branched early or derived/young/branched off last (Omland et al. 2008). Single or variously combined characters could be independently ancestral or derived. Even the speciation supertraits, as a basic taxonomical tool to delineate siblings, cannot help alone in reticulation. Phylogenies of extant species show relationships among evolutionary cousins, when describing trees and deter- mine which characteristics are ancestral or derived. According to genealogical discordance, at all levels of taxonomic hierarchy, every homologous phenomic traits or nucleotide position may have their own true tree-like history, and infinite number of other traits have tracked different histories. The reality of phylogenetic trees is highly questioned, almost certainly reticulated. Recognising reticulation is only a question of resolution in this gene cloud realm. Therefore, along the continuum of the permanent integrative organisation, taxa could be established only as an exclusive group of organisms forming clade for the plurality of the genome (more than any conflicting set) with approximate matching of ecological, evolutionary and morphological entities. Anyhow, ranking alone this dynamic continuum is definitely a semisubjective endeavour (Baum 2009).

Most of the characters with interactive histories are organised as random, but systemic byproducts of stochastic integrative organisation. The amazing plasticity and robustness of living organisms, the innumerable mechanisms to recover from adverse condition are driven by selfdetermination and organisational closure of autonomy. Autonomous systems are operationally closed. Autonomy of biological emergencies is grounded in thermodynamics and functions around fluctuating equilibrium to maintain, by agency, the integer state of emergent closure of constraints against disintegrative external and internal impacts (Moreno \& Mossio 2015).

Early branching of genomic lineages without empirical data does not signify ancestral traits (Crisp \& Cook 2005). Speciation rates differ and are most frequently individual in lineages; morphological differences do not reflect time differences. Slow rates of certain characters do not mean that speciation in a lineage as a whole slows down. Gene tree building complicates further lineage ranking. Relation between gene trees and their containing species trees magnify difficulties how to reconstruct species trees from gene tree ranking with a cloud of gene histories (Maddison 1997). This gene cloud might disagree with the 
species phylogeny produced by discordant processes of horizontal transfer, hybridization, introgression, lineage sorting, undetected gene duplication and extinction. Incomplete lineage sorting inversed in deep coalescence might fail to coalesce until deeper than previous speciation events. Ancestral polymorphisms persist through several speciation events. The biological species concept permits paraphyly, distorts character ranking when historical splits take place by shifting to new ecological niche and diverged in morphology, without reproductive isolation (Velasco 2008). This appropriate ranking is further complicated by attribution of these "biospecies" properties to higher taxa. Phylogeny is an inference product as well as taxonomy is a product of human judgment.

Why unweighted character is inaccurate? Characters and traits should not be considered of equal value in a phylogenetic analysis. For instance, the phylogenetic incipient species is recognised by the diagnostic character of speciation traits. This adaptive structure manifesting the reproductive barrier of the biological species concept has high value in species delineation. Speciation super trait alone is capable to delimit species boundaries already at around the initial split of divergences. Nevertheless, both pheneticists and cladists prefer to apply large set of evidence be considered. All comparative characters have potential value in constructing classifications. This quantitative masking procedure of applying as much number of trait evidence as possible does not take enough care on apomorphic characters of "evolutionary novelties" which are inherently more informative about phylogenetic relations. We have to realise a value judgement stating that one character is a better indicator of phylogeny than another. Weighting could be implicit versus explicit, a priori versus a posteriori, equivalent versus differential (Wheeler 1986) as well as extrinsic versus intrinsic. Information rich character is enriched in extrinsic (not obtainable from matrix) character weighting procedure by adding a priori biological and evolutionary information. The so called "objective" methods practiced in molecular phylogenies do not incorporate such information, accumulated as prior knowledge on the taxa, in order to "remove personal bias" from their taxonomies (Rodrigo 1989). However, the factual reason behind the scene is not this anti-bias excuse: good science is based on intuitive personal biases! The real reason is that "objective" algorithms in molecular phylogeny are unable to incorporate falsifiable empirical phenomics because there is still very little knowledge of the molecular linkage and of the mechanisms of transformation of morphological characteristics (Vogt 2002). Variation of most morphological characters is computable, easily disposable to cladistics. They are continuous quantitative variables, regardless of whether they are coded qualitatively or quantitatively by systematists (Wiens 2001).

\section{Ranking by parameres in Limnephinae subfamily}

Tribe definitions in the Limnephilinae subfamily are fairly subtle, not stable and based on rather general statements (Schmid 1955): (1) Limnephilini tribe is characterised by pattern of anastomose disposition, by massive male genitalia and by appendages on female genitalia; (2) Stenophylacini tribe is characterised only by male genitalia that are less massive and more variable; (3) Chaetopterygini tribe has genitalia similar to Stenophylacini, but characterized by robust and spiny body features; (4) Chilostigmatini tribe is rather isolated by particular genital features. (5) Only Hesperophylacini, a newly established tribe has been grouped inside the Limnephilinae subfamily by paramere organisation: the three species of the tribe have short paramere shaft and armed apically with broom-like burst of strongly sclerotized, recurved spines (Vshivkova et al. 2007). The presence and structure of this particularly organised paramere at the three genera is well grounded in this new tribe (Ruiter 1999, Ruiter \& Nishimoto 2007).

We have revised several genera in the Chaetopterygini and Stenophylacini tribes either by paraprocts or by parameres as speciation traits, directly involved in reproductive isolation (Oláh 
et al. 2015). In the revision of Drusinae subfamily there are ancestral divergences detected in paramere structures with single spine organising centre and applied for species group ranking inside the Drusus genus. These divergences in Drusus genus have followed an earlier split in the paramere prepattern which resulted in the duplication of spine organising centre creating the Ecclisopteryx genus. Based on paramere structure the Anisogamodes genus was removed from the Stenophylacini tribe and placed in the Limnephilini tribe (Grigorenko 2002). The Rhadicoleptus genus was removed from the Limnephilini tribe and placed into the Stenophylacini tribe by its particular paramere (Oláh et al. 2015). Divergences in paramere structures proved to have ranking capacity also in Dicosmoecinae subfamily (Oláh et al. 2018).

Inevitable future revision. It seems that paramere organisation, ancestral and contemporary together, as an adaptive structure in sexual selection mechanisms, has natural ranking capacity in lineage divergences in the entire Limnephilinae subfamily, similarly to the Drusinae subfamily. We follow the Williston's (1914) principle, the Gregory's (1935) general evolution pattern of reduction in structural parts as well as the principle that complexity may function not only by incremental addition but also by incremental subtraction. Our working hypothesis for paramere organisation inside the Limnephilidae family is built upon (1) the ancestral and general as higher rank; (2) complex as ancestral (3) adaptive represents highly weighted trait.

These principles have given orientation to compensate the inadequacy of the single character applied for ranking. Moreover, our single character is a speciation super trait. Based upon these principles here we briefly list the possible relevant transformational series of paramere organisation inside the tribes. The transformation series starts from a more complex character state of ancestral divergences of the tribes and leads to simplification by abbreviation and compaction or to the complete paramere lost in most tribes. Below we present an outline as a working hypothesis for a future comprehensive and systemic paramere revision inevitable to carry out in the Limnephilinae subfamily.

Limnephilini tribe. Basic pattern (plesiomorphic) of parameres are (1) rod-like ending usually in dilated and enlarged bilobed apex produced by apical setose lobes/branches of subapical (proximal)/apical (distal) position; lobes/branches are variously shaped, curved and directed. Apical setae present as unmodified fine structures and/or variously modified spine-like structures (Anabolia, Anisogamodes, Arctopora, Asynarchus, Clistoronia, Glyphotaelius, Grammotaulius, Lenarchus, Lepnevaina, Limnephilus, Platycentropus); one lobe occasionally membranous erectile (Limnephilus). (2) This basic pattern of rod-like paramere with apical complex of setose lobes/ branches could be modified with simplification forming a slender or broadened enlarged apical portion without any lobes or branches, but with less modified setae present (Anabolia, "Colpotaulius", Clistoronia, Leptophylax, Nemotaulius, Philarctus, Rivulophilus). (3) Further simplification produced simple spiniform paramere shaft with only few setal structures ("Astratus"). (4) Simplification produces spiniform paramere shaft without any structure of setal origin ("Zaporota"). (5) Final stage leads to paramere lost ("Astratodes").

Chilostigmini tribe. Basic pattern of parameres are rather simple thin spiniform, almost filiform without branches, lobes or setal structures. The dominating slender, slim, spiniform basic pattern the parameres is modified in a few genera to abbreviated thick pattern and almost lost vestigial in one genus. (1) Paramere slender, slim, spiniform: Brachypsyche, Chilostigma, Chilostigmodes, Desmona, Grensia, Psychoglypha; (2) Paramere abbreviated thick and much shorter than aedeagus: Frenesia, Glyphopsyche; (3) Paramere lost: Homophylax

Chaetopterygini tribe. (1) Basic pattern of paramere rod-shaped with setal structures: Chaetopteroides, Chaetopteryx; (2) Paramere rodshaped without setal structures: Psilopteryx; (3) 
Paramere enlarged without setal structures: $B a$ dukiella; (4) Paramere abbreviated thin: Rizeiella; (5) Paramere lost: Annitella, Chaetopterygopsis, Chaetopteryx morettii, Kelgena, Pseudopsilopteryx.

Stenophylacini tribe. Basic pattern of parameres are spiniform without apical branches, lobes, but with variously developed or vestigial spine-like modified setal structures. Setal structures develop in various basal, apical and between positions along the paramere shaft. The reduction of setal structures frequently occurs inside the same genus. The paramere shaft may undergo enlarging, thickening, abbreviation or could be almost lost as vestigial thread-like structure (Hydatophylax).

Hesperophilacini tribe. Basic pattern of parameres is characterized by short shaft, apically with broom-like burst of strongly sclerotized, recurved spines.

\section{TAXONOMY}

\section{Agaphylax gen. nov.}

Diagnosis. Medium sized animals with stenophylacini rather than limnephilini habitus: (1) forewing is broad, not elongated; (2) forewing termen is convex, not truncate or concave; (3) genitalic structures are not robust. This new genus is established here only by a single trait, by the uniquely organised basic pattern of the parameres. This short abbreviated paramere with vertically flattened basal body is characterized by the ramose apical ending; this ramose apical region of the paramere is composed of the upright directed leading arm of the short and flat shaft and of the ramification on the apicoventral angle represented by varying number of small arms; the entire paramere is without any setal structure.

The upright directed ramose paramere of the Agaphylax is unique in the Limnephilinae subfamily. Mesophylax parameres may have some resemblance, but Mesophylax parameres are (1) "curving" upward, not "right angled" upward; (2) rod-shaped, not flattened; (3) they are not ramose. Moreover, Mesophylax species have uniquely organised bilobed cerci and paraproct complex, the only generic character complex distinguishing Mesophylax from the related genera of Stenophylax including Micropterna.

Agaphylax has simple undivided cerci and differently organised paraproct. The combination of cerci-paraproct-paramere triple complex results in a generic level divergence additional to the unique paramere organisation. Difficulties arise because every species is a mix of ancestral and derived characteristics. Single or variously combined characters could be independently ancestral or derived.

Type species. Agaphyalax balcanicus sp. nov.

Etymology. Agaphylax from "ág” branch, "ágas" ramose in Hungarian refers to the branching, ramose apical region that is the head of the paramere and from "phylax" guard in Greek.

\section{Agaphyalax balcanicus sp. nov.}

(Figures 1-20)

Material examined. Holotype: Macedonia, Pelagonia region, Pelister Mts, Capari, springs area

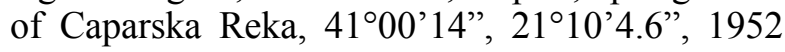
m, 13.IX.2016, leg. P. Juhász, T. Kovács \& G. Szilágyi (1 male, OPC). Allotype: same as holotype (1 female, OPC). Paratypes: Macedonia, Pelagonia region, Bitola municipality, Pelister Mts, Capari, spring area of Caparska Stream, $1955 \mathrm{~m}$, N41 ${ }^{\circ} 00.227^{\prime}$ E $21^{\circ} 10.075^{\prime}, 3 . X .2017$, P. Juhász, T. Kovács \& D. Murányi (3 males, 6 females, OPC; 1 male, 1 female, DBFMNSUP; 1 male, 1 female, RPC; 1 male, 1 female, SMNH). Macedonia, Pelagonia region, Bitola municipality, Pelister Mts, Dva Groba, spring of Maloviška Stream, 2060 m, N4059.113' E21 1010.100', 3.X.2017, P. Juhász, D. Murányi, T. Kovács (3 males, OPC; 1 male MMHNHM).

Depositories. Department of Biology, Faculty of Mathematics and Natural Sciences, University of Prishtina, Prishtina, Kosovo (DBFMNSUP). 


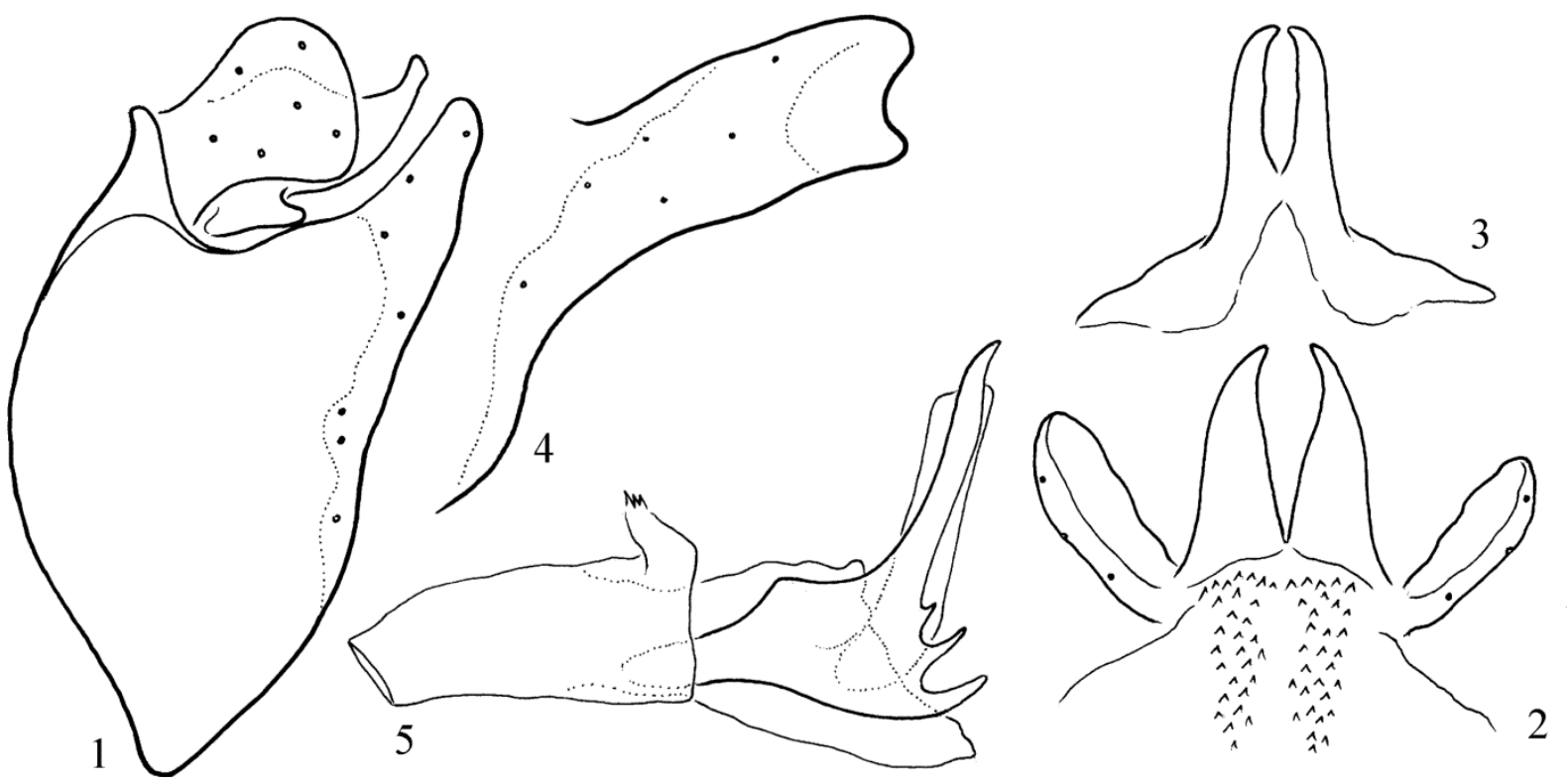

Figures 1-5. Agaphylax balcanicus sp. nov. Holotype male: 1 = genitalia in lateral view; 2 = genitalia in dorsal view; 3 = paraproct in caudal view; 4 = left gonopod in caudal view; $5=$ phallic organ in lateral view.

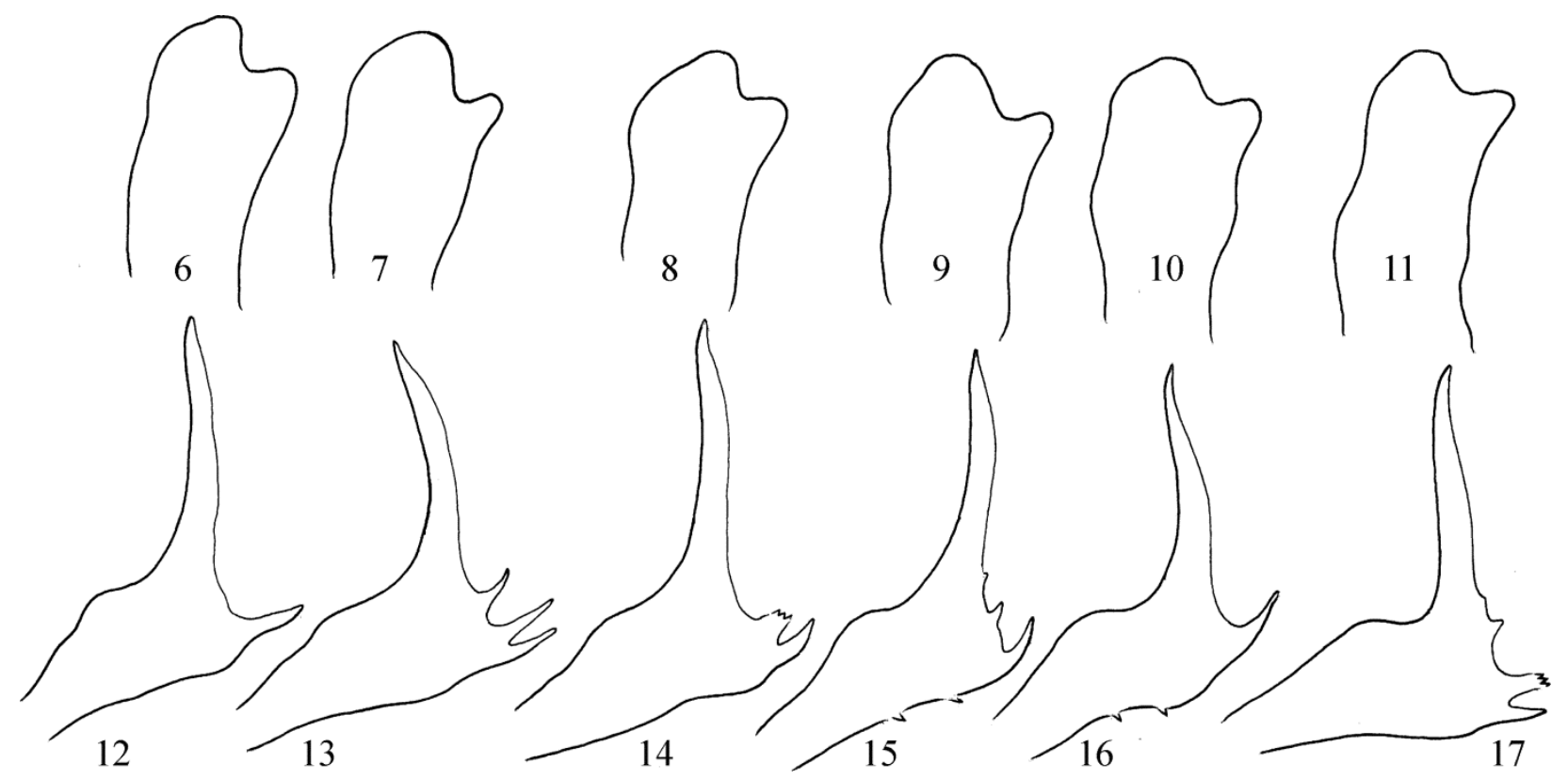

Figures 6-17. Agaphylax balcanicus sp. nov. Paratypes males: 6-7 = gonopod apex in caudal view, population from spring area of Caparska Reka; 8-11 = gonopod apex in caudal view, population from the spring of Maloviška Stream; 12-13=left paramere in lateral view, population from spring area of Caparska Reka; 14-17 = left paramere in lateral view, population from the spring of Maloviška Stream. 
Mátra Museum of the Hungarian Natural History Museum (MMHNHM) Oláh Private Collection, Debrecen, Hungary, under national protection by the Hungarian Natural History Museum, Budapest (OPC). Ruiter Private Collection (RPC). Swedish Museum of Natural History, Stockholm, Sweden (SMNH).

Description. Male (in alcohol). Forewing membrane brown, slightly spotted, covered with small thin setae in recumbent position; forewing veins armed with upright erected strong setae; forewing length $13 \mathrm{~mm}$. Spur number 123. Head and thoracic sclerites as well as antennae, labial and maxillary palps and femurs are dark castanean brown; first maxillary palp segment of male is yellow, legs yellowish, slightly darkening gradually towards apical segments.

Male genitalia. The pegged, spinulose apicomedian zone on tergite VIII is composed of a pair of horizontally elongated bands of black pegs. Lateral profile of segment IX and the fused gonopod subtriangular. Cerci large circular with some constricted basal region forming a discernible stalk. Dorsal branch of the paraproct vertically flattened plate-like, bellied and tapering apicad in lateral view; the ventral branches of the paraproct do not meet mesad, separated triangular in caudal view. Gonopods elongated upright, its apical region slightly tapering, blunt triangular in lateral view; apex excised bilobed in caudal view, lobes highly varying in the same population, usually the lateral broader. Phallic organ composed of the phallotheca, endotheca, aedeagus, endophallus and the paramere. The aedeagus short and broad less sclerotized, rather membranous. The endophallus more sclerotized and upright directed, similarly right angled as the dorsoapical leading arm of the paramere. The paramere short, abbreviated with vertically flattened basal body; the paramere head that is the apical region of the paramere composed of the upright directed leading arm of the short and flat shaft and ramification on the apicoventral angle by varying number of small arms; the right angled leading arm as long as the paramere body; the entire paramere without any setal structure.

Female (in alcohol). Forewing membrane brown, slightly spotted, covered with small thin setae in recumbent position; forewing veins armed with upright erected strong setae; forewing length $13 \mathrm{~mm}$. Spur number 123. Head and thoracic
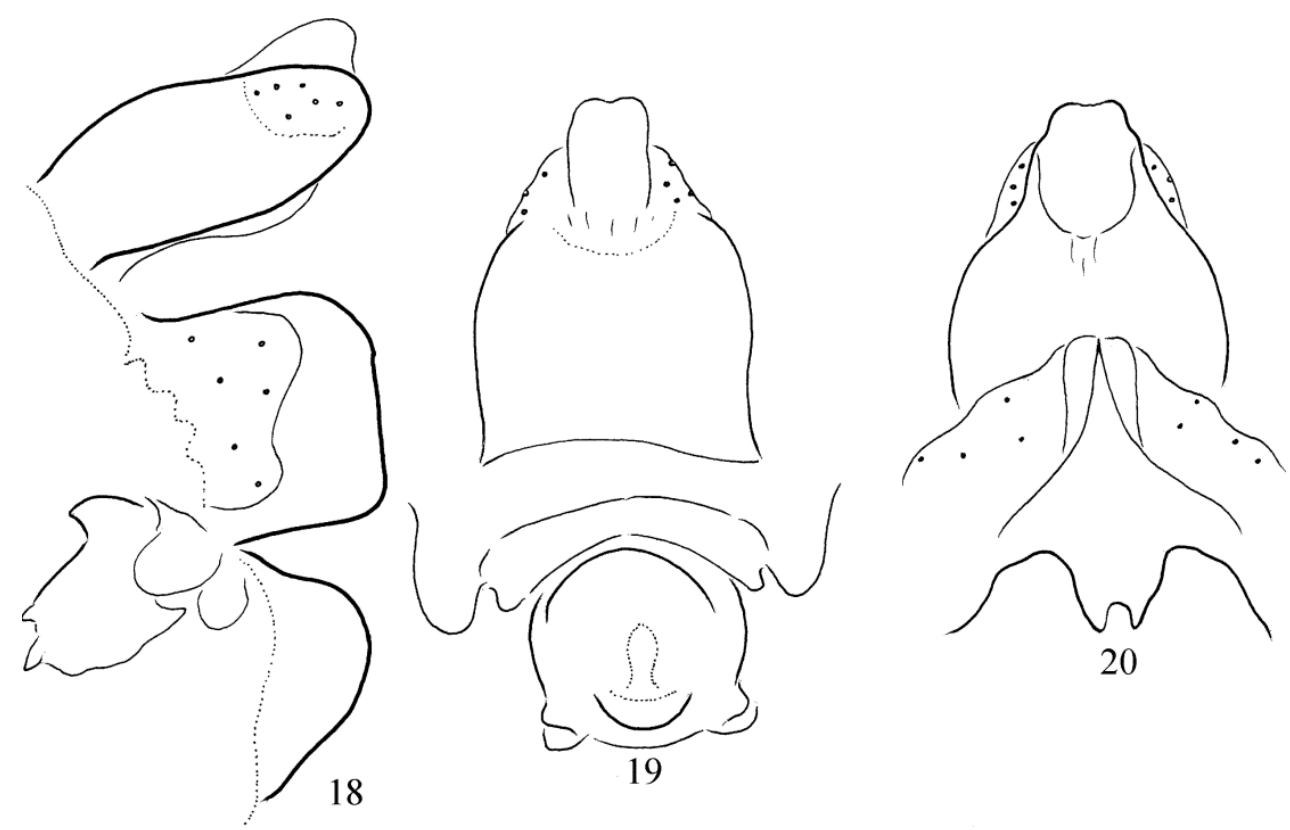

Figures 18-20. Agaphylax balcanicus sp. nov. Allotype female: 18 = genitalia in lateral view; 19 = genitalia in dorsal view; 3 = genitalia in dorsal view; $20=$ genitalia in ventral view. 


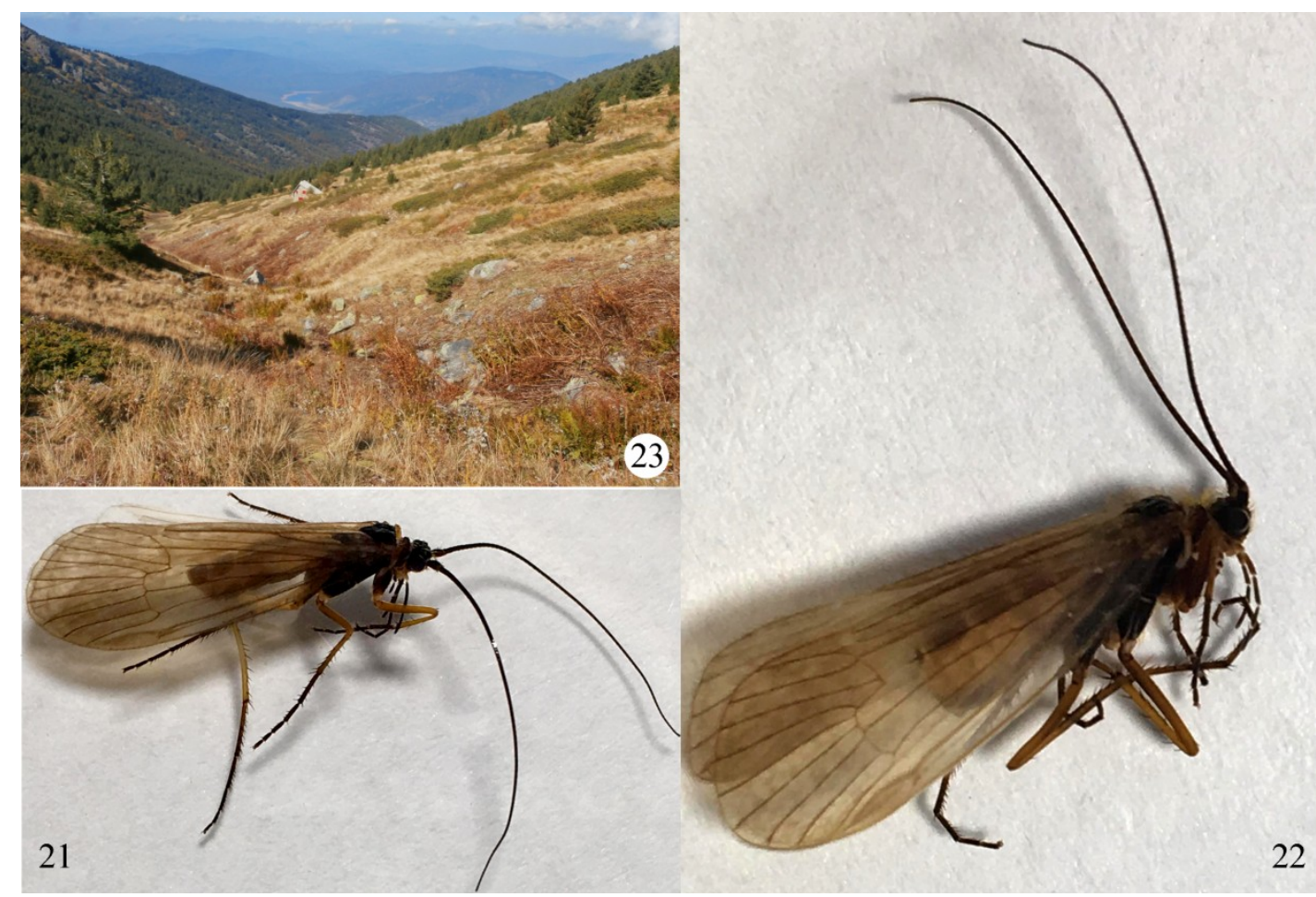

Figures 21-23. Agaphylax balcanicus sp. nov. 21 = habitus photo of the male; 22 = habitus photo of the female; $23=$ habitat.

sclerites as well as antennae, labial and maxillary palps and femurs dark castanean brown; legs yellowish, slightly darkening gradually towards apical segments.

Female genitalia. Tergite IX forming a tube together with the less sclerotized tergite $\mathrm{X}$ encircling anus, apicolateral setose area on tergite IX small; the sternite of segment IX less sclerotized covered with few setae. Supragenital plate of sternum X well-developed into triangular smooth and glabrous surface in ventral view. Median lobe of the vulvar scale (lower vaginal lip) small, but present. Vaginal sclerite complex short. The dorsal articulation sclerites much developed, that is the sclerotized internal continuation of the supragenital plate (upper vulvar lip) transversally widened. The internal dorsal articulation sclerites and the external supragenital plate together participate to receive the stimulating or harm effect of the unique ramose parameres.

Etymology. Named after the region of the locus typicus.
Acknowledgements - We highly appreciate and acknowledge the valuable comparative materials of limnephilid specimens provided to our study by David E. Ruiter, OR, USA; John Morse, Clemson University, Arthropod Collection, USA, and Takao Nozaki, Kanagawa Environmental Research Center, Japan.

\section{REFERENCES.}

Avise, J.C. \& LIU, J.-X. (2011): On the temporal inconsistencies of Linnean taxonomic ranks. Biological Journal of the Linnean Society, 102: 707-714. doi: 10.1111/j.1095-8312.2011.01624.x

BAUM, D.A. (2009) Species as ranked taxa. Systematic Biology, 58(1):74-86. doi: 10.1093/sysbio/syp011

Bertrand, Y., Pleijel, F. \& Rouse, G.W. (2006): Taxonomic surrogacy in biodiversity assessments, and the meaning of Linnaean ranks. Systematics and Biodiversity, 4(2):149-159. doi: $10.1017 / \mathrm{S} 1477200005001908$

Bevilacqua, S., Terlizzi, A., Claudet, J., FraSCHETTI, S. \& BoERo, F. (2012): Taxonomic relat 
edness does not matter for species surrogacy in the assessment of community responses to environmental drivers. Journal of Applied Ecology, 49: 357-366. doi: 10.1111/j.1365-2664.2011.02096.x

CRISP, M.D. \& COOK, L.G. (2005): Do early branching lineages signify ancestral traits? Trends in Ecology and Evolurtion, 20(3): 122-128.

doi: $\underline{10.1016 / j . t r e e .2004 .11 .010}$

Esteve-Altava, B., Marugán-Lobón, J., Botella, H., \& RASSKIN-GUTMAN, D. (2013): Structural constraints in the evolution of the tetrapod skull complexity: Williston's law revisited using network models. Evolutionary Biology, 40: 209-219. doi: $\underline{10.1007 / \mathrm{s} 11692-012-9200-9}$

GREGORY, W.K. (1935): Reduplication in evolution. Quarterly Review of Biology, 10: 272-290. doi: $\underline{10.1086 / 394485}$

GRIGORENKO, V.N. (2002): Some taxonomical notes on the limnephiline caddisflies (Trichoptera: Limnephilidae, Limnephilinae). Proceedings of the Xth International Symposium on Trichoptera. In. MEY, W. (Ed.). Nova Supplementa Entomologica, Keltern, 15: 1-664.

LYNCH, M. (2006): The origins of eukaryotic gene structure. Molecuar Biology and Evolution, 23: 450-468. doi: $10.1093 / \mathrm{molbev} / \mathrm{msj} 050$

MadDison, W.P. (1997): Gene trees in species trees. Systematic Biology, 46(3): 523-536. doi: $10.1093 /$ sysbio/46.3.523

MalicKy, H. (2001): Notes on the taxonomy of Rhadicoleptus, Ptilocolepus and Pseudoneureclipsis. Braueria Lunz am See, Austria, 28: 19-20.

Moreno, A. \& Mossio M. (2015): Biological autonomy. A philosphical and theoretical enquiry. Springer, Dordrecht, The Netherlands, $221 \mathrm{pp}$. doi: $\underline{10.1007 / 978-94-017-9837-2}$

OLÁH, J. (2018): Species delineation and description in Aethaloptera Brauer genus by phallic head (Trichoptera, Hydropsychidae, Macronematinae). Opuscula Zoologica, Budapest 49(1): 3-16. doi: 10.18348/opzool.2018.1.3

OlÁH, J., KovÁcs, T., Sivec, I., SzIVÁK, I. \& URBANIC, G. (2012): Seven new species in the Chaetopteryx rugulosa species group: applying the phylogenetic species concept and the sexual selection theory (Trichoptera, Limnephilidae). Folia Historico Naturalia Musei Matraensis, 36: 51-79.
OlÁH, J. \& ITO, T. (2013): Synopsis of the Oxyethira flavicornis species group with new Japanese Oxyethira species (Trichoptera, Hydroptilidae). Opuscula Zoologica, Budapest, 44(1): 23-46.

Oláh, J., Andersen, T., Chvojka, P., Coppa, G., Graf, W., IBrahimi, H., LODOVICI, O., PreVISIC, A. \& VAlle, M. (2013): The Potamophylax nigricornis group (Trichoptera, Limnephilidae): resolution of phylogenetic species by fine structure analysis. Opuscula Zoologica, Budapest, 44(2): $167-200$

OlÁH, J., ChVoJKA, T.P., COPPA, G., Graf, W., IBRAHimi, H., LOdOVici, O., Ruiz Garcia, A., SÁInZBARIÁIN, M., VAlle, M. \& ZAMORA-MuÑOZ, C. (2014): The genus Allogamus Schmid, 1955 (Trichoptera, Limnephilidae): revised by sexual selection-driven adaptive, non-neutral traits of the phallic organ. Opuscula Zoologica, Budapest, 45(1): 33-82.

Oláh, J., Beshkov, S., Chvojka, T.P., Ciubuc, C., COPPA, G., IBRAHIMI, H., KovÁCs, T., MEY, W. \& OLÁH, J. jr. (2017): Revision of Drusinae subfamily (Trichoptera, Limnephilidae): divergence by paraproct and paramere, speciation in isolation by integration. Opuscula Zoologica, Budapest, 48(Suppl. 1): 3-228. doi: 10.18348/opzool.2017.S1.3

Oliver, I. \& BeAtTIE, A.J. (1996): Invertebrate morphospecies as surrogates for species: a case study. Conservation Biology, 10(1): 99-109. doi: 10.1046/j.1523-1739.1996.10010099.x

O'MEARA, B. C. 2010. New heuristic methods for joint species delimitation and species tree inference. Systematic Biology 59(1): 59-73.

OMland, K.E., CoOK, L.G. \& CRISP, M.C. (2008): Tree thinking for all biology: the problem with reading phylogenies as ladders of progress. BioEssays, 30: 854-867. doi: 10.1002/bies.20794

RoDRIGO, A.G. (1989): An information-rich character weighting procedure for parsimony analysis. New Zealand Natural Sciences, 16: 97-103.

Ross, H.H. (1956): Evolution and classification of the mountain caddisflies. The University of Illinois Press, Urbana, 213 pp.

RUITER, D.E. (1999): A new species and new synonym in the genus Psyhoronia (Limnephilidae), with significant records for caddisflies (Trichoptera) from western North America. Great Basin Naturalist, 59(2): 160-168. 
RUITER, D.E. \& Nishimoto, H. (2007): Crenophylax (Trichoptera: Limnephilidae), a new genus to accommodate Rhadicoleptus sperryi Banks, 1943. Proceedings of the Entomological Society of Washington, 109(2): 309-323.

SCHMID, F. (1955): Contribution à l'étude des Limnophilidae (Trichoptera). Mitteilungen der Schweizerischen Entomologischen Gesellschaft, 28: 1-245.

SCHMID, F. (1958): A propos de deaux récents ouvrages sur la phylogénie et la zoogeographie des Trichopteres. Miscellania Zoologica Barcelona, 1: 1-27.

SCHMID, F. (1979): On some new trends in Trichopterology. Bulletin of the Entomological Society of Canada, 11: 48-57.

SCHMID, F. (1998): The insects and Arachnids of Canada. Part 7. Genera of the Trichoptera of Canada and Adjoining or Adjacent United States. NCR Research Press, Ottawa, Ontario, Canada, 319 pp.

SCHMiTT, M. (2016): Hennig, Ax, and present-day mainstream cladistics, and polarising characters. Peckiana, 11: 35-42.

VShIVKOVA T.S. (2006): Phylogeny of family Limnephilidae (Insecta: Trichoptera) with emphasis on tribe Limnephilini (Subfamily Limnephilinae). Ph.D. Thesis. Clemson University, UMI Dissertation Services, $686 \mathrm{pp}$.

Vshivkova, T.S., Morse, J.C. \& RUTTER, D. (2007): Phylogeny of Limnephilidae and composition of the genus Limnephilus (Limnephilidae: Limnephilinae,
Limnephilini). Proceedings of the XIIth International Symposium on Trichoptera. In. BUENO-SORIA, J., Barba-Álvarez, R. \& Armitage, B. (Eds). The Caddis Press, Columbus, p. 309-319.

VELASCO, J.D. (2008): Species concepts should not conflict with evolutionary history, but often do. Studies in History and Philosophy of Biological and Biomedical Sciences, 39: 407-414. doi: $\underline{10.1016 / j . s h p s c .2008 .09 .007}$

VoGT, L. (2002): Testing and weighting characters. Organism Diversity \& Evolution, 2: 319-333. doi: $\underline{10.1078 / 1439-6092-00051}$

WHEELER, Q.D. (1986): Character weighting and cladistic analysis. Systematic Zoology, 35(1): 102109.

WIENS, J.J. (2001): Character analysis in morphological phylogenetics: problems and solution. Systematic Biology 50(5):689-699. doi: $\underline{10.1093 / \text { sysbio/35.1.102 }}$

Williston, S.W. (1914): Water Reptiles of the past and present. University of Chicago Press, Chicago, 251 pp. doi: $10.5962 /$ bhl.title. 44842

WINTHER, R.G. (2009): Character analysis in cladistics: abstraction, reification, and the search for objectivity. Acta Biotheoretica, 57: 129-162. doi 10.1007/s10441-008-9064-7

YI, S.V. (2006): Non-adaptive evolution of genome complexity. Bioessays, 28: 979-982. doi: $\underline{10.1002 / \text { bies.20478 }}$ 